\title{
Quality improvement study on early recognition and intervention of caregiver burden in a tertiary hospital
}

\author{
Rachel Marie Towle (D , ${ }^{1}$ Lian Leng Low, ${ }^{2}$ Siok Bee Tan, ${ }^{3}$ Cristina Hendrix ${ }^{4}$
}

To cite: Towle RM, Low LL, Tan SB, et al. Quality improvement study on early recognition and intervention of caregiver burden in a tertiary hospital. BMJ Open Quality 2020;9:e000873. doi:10.1136/ bmjoq-2019-000873

Received 2 November 2019 Revised 9 June 2020 Accepted 29 June 2020
Check for updates

(C) Author(s) (or their employer(s)) 2020. Re-use permitted under CC BY-NC. No commercial re-use. See rights and permissions. Published by BMJ.

${ }^{1}$ Nursing, SingHealth Regional Health Service, Singapore General Hospital, Singapore ${ }^{2}$ SingHealth Regional Health Service; Family Medicine and Continuing Care, Singapore General Hospital, Singapore ${ }^{3}$ Nursing, Singapore General Hospital, Singapore

${ }^{4}$ Duke University School of Nursing; Durham Veterans Affairs GRECC, Durham, NC, USA

Correspondence to Dr Rachel Marie Towle; rachel.marie.towle@sgh.com.sg

\section{ABSTRACT}

Background Caregivers play a crucial role in taking over the important task of looking after patients post-hospitalisation. Caregivers who are unfamiliar with patients' post-discharge care often experience caregiver stress, while patients may see deterioration in their condition. As caregivers are our core partners in healthcare, it is therefore necessary for patient navigators to recognise, assess and address caregivers' needs or burden as early as on admission to hospital. Patient navigators are trained registered nurses whose main role is to provide patients and caregivers with personalised guidance through the complex healthcare system. Objectives This quality improvement study examined the efficacy of using the Zarit Burden Interview as a tool in helping patient navigators recognise caregiver burden early and the effectiveness of targeted interventions on caregiver burden.

Methods Various quality improvement tools were used. Eighty-six patient-caregiver dyads who met the inclusion criteria were enrolled. Informal caregivers were assessed for caregiver burden using the Zarit Burden Interview during hospital admission (TO) and again at 30 days postdischarge (T1), post-intervention.

Results There was significant improvement in the Zarit Burden mean scores from T0 to T1 reported for the 80 dyads who completed the study, even after adjusting for covariates (T0 mean $=11.08, \mathrm{SD}=7.64 ; \mathrm{T} 1$ mean $=2.48$, $\mathrm{SD}=3.36$, positive ranks, $\mathrm{p}<0.001$ ). Highest burden identified by most caregivers were the personal strain; trying to meet other responsibilities and uncertain about what to do in caring for their loved one. By recognising the different aspects of caregiver burden early, patient navigators were able to focus their interventions. Conclusion Early recognition of caregiver burden and targeted interventions were found to be effective at reducing caregiver burden in a tertiary hospital.

\section{INTRODUCTION}

Amid a rapidly changing healthcare landscape in Singapore-an ageing population, burden of chronic disease and a shrinking healthcare workforce ${ }^{1}$ - the reliance on caregivers to continue the care of patients after hospital discharge is increasing. Over the years, caregivers have taken up the roles of nurse extenders, performing complex tasks such as medication management, injections, wound care, tube feeding among others, without the benefit of any formal education or training. ${ }^{2}$ Consequently, many caregivers felt unprepared to assume this role post-hospitalisation. ${ }^{3}$ Although caregivers are the force multiplier of our healthcare system, the significance of their role and its consequences such as related strain and compromised caregiver's health are often overlooked by hospital staff. ${ }^{4}$ Moreover, when a patient is hospitalised, the caregiver is often overwhelmed by a great amount of information from various healthcare staff and the physical demands of caring for their loved one at home.

Caregivers who are unfamiliar with patients' post-discharge care often experience caregiver stress, while patients may see deterioration in their condition. Many get readmitted to hospital, have poor quality of life and even premature admission to nursing homes. ${ }^{5}$ Common problems experienced by caregivers at home are performing multifaceted activities and roles that evolve around the daily demands of the chronic disease, maintaining caregiver physical, emotional, social, spiritual and financial well-being, having insufficient caregiver support and performing caregiving with uncertainty and inadequate knowledge. ${ }^{6}$

Caregivers who are severely burdened may also be impeded in their role and not be able to function effectively, especially in supporting the patient. ${ }^{7}$ The patient's own state of physical and mental well-being may be adversely affected as a result, ${ }^{89}$ leading to hospital readmission or early institutionalisation. ${ }^{10}$ However, caregivers who were involved in early discharge planning and patient care following hospitalisation had reported being in better general health 2 weeks following the patient's hospitalisation, more accepting of their caregiving role, less negative about caregiving, strengthened in their caregiving competence and reduced harm to the patient under their care. ${ }^{1112}$ The review of nearly 100 studies published between 1985 and 2001 also reported that a breakdown in care during 
the transition from hospital to home often resulted in negative outcomes such as decline in physical health. ${ }^{13}$ However, when prompt support was offered to caregivers, burden and other depressive symptoms were significantly eased during and after hospitalisation. ${ }^{14}$

Because of the complexity in coordinating the multidimensional needs of patients during hospital admission, a centralised person who oversees specific patients from hospitalisation through discharge and into the community is needed. For this reason, the patient navigator (PN) role was initiated in the Singapore Healthcare cluster in 2014 with the aim to provide patients and caregivers with personalised guidance through the complex healthcare system; from tertiary to community, primary and home care. ${ }^{15} \mathrm{PN}$ main roles are conducting care assessment, coordinate discharge planning and post discharge follow-up via telephone calls and home visits for up to 30 days for care continuity. Although PNs play an important role in care coordination and care transition, they lack the necessary tools and skills to properly assess caregiver well-being including the level of caregiver burden. As caregivers are our core partners in healthcare, it is therefore necessary for PNs to be able to recognise, assess and address caregivers' needs as early as on admission. Hence, the purpose of this quality improvement study was to examine the efficacy of using the Zarit Burden Interview (ZBI) as a tool for PNs in the early recognition and intervention of caregiver burden in a tertiary hospital.

\section{METHODOLOGY}

\section{Participants}

The participants in this study were informal caregivers of patients admitted to a tertiary hospital in Singapore and enrolled by PNs between the periods of 2 August 2017 and 10 October 2017. Eligible caregivers were unpaid caregivers involved in the patients' care or involved in decision-making on the patients' behalf (eg, decisions on health-related matters such as doctor's appointments and medications, financial matters and activities of daily living (ADL)). Eligible patients were patients with at least one chronic disease, needed permanent assistance in at least one of the ADL such as bathing, eating, transferring, continence, dressing or toileting, and were returning home after discharge from hospital and not to an institutional care facility, such as a nursing home or a community hospital. Patients and caregivers who did not want to be contacted postdischarge, non-residents and leaving Singapore after discharge were ineligible.

\section{Planning and intervention}

The team members were selected based on their interest and key roles in the clinical field. Once the team was formed, members met every fortnightly to discuss and brainstorm the Plan, Do, Study, Act cycles. The Gantt chart was plotted to aid and guide the team in scheduling the different phases of the entire project. Various quality improvement tools such as the Cause and Effect Diagram, Pareto Chart, Tree Diagram and Prioritisation Matrix were used to aid the team in this quality improvement journey. The tools facilitated generation of new ideas in a systematic and well-structured manner. This project was implemented in all inpatient wards (medical and surgical) in a tertiary hospital and continued with a 30-day postdischarge follow-up by the PN. The study added the ZBI tool as part of the PNs' care assessment protocol during hospital admission to objectively measure caregiver burden. Caregivers and patients who were eligible were reviewed by the PN in the ward and verbal consent to participate in the study was obtained. This was followed by a face-to-face interview for the dyads' demographic details and the self-administered ZBI.

The interventions were carried out in three stages. Intervention 1 adapted the validated ZBI 12-items as an assessment tool to properly measure caregiver burden. Using a validated tool may be more effective in identifying problems than an unstructured clinical question thereby assisting the PN in clinical decision making. Intervention 2 included the targeted PN interventions.

\section{Table 1 Patient navigator (PN) targeted interventions}

\begin{tabular}{ll}
\hline Main aspects & Targeted PN interventions \\
\hline Reducing the amount of caregiving & Referral to community services such as day care/day rehabilitation/respite/ \\
(ZBI Q1, Q2, Q3, Q4, Q5, Q6, Q7, Q8, Q9) & interim caregiver support, befriender, etc. \\
& Application and purchase/rental of medical devices to aid caregiving. \\
& Affirmation and encouragement to caregivers. \\
& Engagement in regular physical activity, health screening/checks, taking short \\
& vacation, etc. \\
& Referral and engagement with caregiver support groups. \\
& Multicomponent psycho-social-emotional counselling by trained healthcare \\
& staff (medical social worker, psychologist, nurse counsellor, case manager, \\
& etc). Either individual or family. \\
Improving caregiving skills & Provide an individualised one-to-one/institutional-level caregiver training. \\
(ZBI Q10, Q11, Q12) & Chronic disease and medication education and empowerment. \\
& Application for financial assistance or financial counselling. \\
& Transitional homecare postdischarge.
\end{tabular}


Table 2 Demographical description of caregivers $(n=86)$

Number of caregivers

Caregiver demographics $(n=86)$

$\begin{array}{lc}\text { Age (years) } & \\ <40(\%) & 9(10.5 \%) \\ 41-60 \text { years }(\%) & 33(38.4 \%) \\ 61-80 \text { years }(\%) & 37(43.0 \%) \\ >80 \text { years }(\%) & 7(8.1 \%)\end{array}$

Gender

$\begin{array}{ll}\text { Female (\%) } & 53(61.6 \%) \\ \text { Male (\%) } & 33(38.4 \%)\end{array}$

Race

Chinese (\%) $75(87.2 \%)$

Malay (\%) $9(10.5 \%)$

Indian (\%)

$2(2.3 \%)$

Marital status

Married (\%) 56 (65.1\%)

Single (\%)

$26(30.2 \%)$

Separated/Divorced/Widowed (\%)

$4(4.7 \%)$

\begin{tabular}{lc} 
Education & \\
\hline No formal education (\%) & $19(22.1 \%)$ \\
\hline Primary school (\%) & $17(19.8 \%)$ \\
Secondary school (\%) & $48(55.8 \%)$ \\
\hline Tertiary (college/polytechnic/university) (\%) & $2(2.3 \%)$
\end{tabular}

Employment

\begin{tabular}{lc} 
(\%) Working full time (\%) & $44(51.2 \%)$ \\
\hline Looking for job (unemployed) & $26(30.2 \%)$ \\
\hline Working part time (\%) & $9(10.5 \%)$ \\
Home-maker (\%) & $4(4.7 \%)$ \\
Retired (\%) & $3(3.5 \%)$
\end{tabular}

Living arrangement

Living together (\%) $\quad 61(70.9 \%)$

Living apart (\%)

$25(29.1 \%)$

Duration of caregiving

$<1$ month (\%)

$4(4.7 \%)$

1-12 months (\%)

$5(5.8 \%)$

$1-2$ years (\%)

$6(7.0 \%)$

$>2$ years $(\%)$

$71(82.6 \%)$

Relationship between caregiver and recipient

$\begin{array}{lc}\text { Daughter/Son (\%) } & 53(61.6 \%) \\ \text { Spouse (\%) } & 24(27.9 \%) \\ \text { Relative or close friend (\%) } & 6(7.0 \%) \\ \text { Grandchild (\%) } & 2(2.3 \%) \\ \text { In-law (\%) } & 1(1.2 \%)\end{array}$

Living with foreign domestic worker

No $(\%)$

$46(53.5 \%)$

Continued
Table 2 Continued

\begin{tabular}{ll}
\hline Caregiver demographics & $\begin{array}{l}\text { Number of } \\
\text { caregivers } \\
\text { (n=86) }\end{array}$ \\
\hline \multicolumn{1}{|c|}{ Yes (\%) } & $40(46.5 \%)$ \\
\hline $\begin{array}{l}\text { Other responsibilities } \\
\text { Work commitments (\%) }\end{array}$ & $34(39.5 \%)$ \\
$\begin{array}{l}\text { None (\%) } \\
\text { Taking care of own family with small } \\
\text { children (\%) }\end{array}$ & $18(25.1 \%)$ \\
$\begin{array}{l}\text { Taking care of another ill or elderly person } \\
\text { at home (\%) }\end{array}$ & $5(5.8 \%)$ \\
\hline \begin{tabular}{l} 
Others (\%) \\
\hline
\end{tabular} & $4(4.7 \%)$ \\
\hline
\end{tabular}

The interventions were divided into two main aspects: those targeted at reducing the amount of caregiving and those targeted at improving caregiving skills. ${ }^{16}$ The targeted interventions to reduce the amount of caregiving included making referrals to community step-down services such as day care centre or a rehabilitation centre; home help services; interim caregiver support and application of medical devices such as hospital bed, pressure relieving air mattress, home oxygen apparatus, suction machine, commode, hoist among others to ease the physical burden of caregiving. Interventions to improve caregiving skills included: an individualised caregiver training on basic care and nursing skills; chronic disease and medication management; psychoemotional counselling and financial assistance from a medical social worker (table 1). The caregiver training was focused and interactive; caregivers asked questions, discussed scenarios and participated in the hands-on practical sessions. The training was conducted by the nurses or therapist, each lasted 2-3 hours and a follow-up review at the patient's bed-side was arranged if required. Lastly, intervention 3 included capability building and training, where PNs received three sessions ( 3 hours each) of training by a trained psychologist and medical social worker. Training topics included understanding behavioural and psychological issues in patients with mental health issues, communication skills, community resources (where to find help), basic counselling skills, caregiver support guide and taking care of one's mental health.

When patients were discharged home, the PN followed up with postdischarge telephone calls and home visit within three working days. The follow-up duration of 30 days aligned with the hospital's definition of hospital readmission within 30 days. All dyads received a minimum of one telephone call and one home visit within the first week of discharge. Caregivers who had higher burden received more regular telephone calls and home visits. The frequency of the telephone calls and home visits depended on the dyads' care needs and the clinical assessment of the PN. It can range from twice weekly to once a month. During the home visit, the PN provided 
Table 3 Demographical description of patients $(n=86)$

\begin{tabular}{lc}
\hline Patient demographics & $\begin{array}{l}\text { Number of } \\
\text { patients }(\mathbf{n}=\mathbf{8 6})\end{array}$ \\
\hline $\begin{array}{l}\text { Age (years) } \\
<40(\%)\end{array}$ & $1(1.2 \%)$ \\
$41-60(\%)$ & $5(5.8 \%)$ \\
$61-80(\%)$ & $31(36.1 \%)$ \\
$>80$ years $(\%)$ & $49(57.0 \%)$
\end{tabular}

Gender

\begin{tabular}{lc} 
Female (\%) & $56(65.1 \%)$ \\
Male (\%) & $30(34.9 \%)$ \\
Race & $75(87.2 \%)$ \\
$\quad$ Chinese (\%) & $9(10.5 \%)$ \\
$\quad$ Malay (\%) & $2(2.3 \%)$ \\
$\quad$ Indian (\%) & \\
Modified Barthel Index & $11(12.8 \%)$ \\
$<10$ (severe disability) (\%) & $48(55.8 \%)$ \\
$<15$ (moderate disability) (\%) & $27(31.4 \%)$ \\
\hline 16 (independent) (\%)
\end{tabular}

Number of comorbidities

\begin{tabular}{|cc|}
\hline$<2$ (\%) & $8(9.3 \%)$ \\
\hline $2-5(\%)$ & $36(41.9 \%)$ \\
\hline$>5$ (\%) & $42(48.8 \%)$ \\
\hline Abbreviated Mental Test & \\
\hline $0-3$ (severe impairment) (\%) & $21(24.4 \%)$ \\
\hline $4-6$ (moderate impairment) (\%) & $13(15.1 \%)$ \\
\hline$>6$ (mild/no impairment) (\%) & $52(60.5 \%)$ \\
\hline Number of medications & \\
\hline$<5$ (\%) & $11(12.8 \%)$ \\
\hline $5-10$ (\%) & $42(48.8 \%)$ \\
\hline$>10$ (\%) & $33(38.4 \%)$ \\
\hline Clinical frailty score & \\
\hline Very fit (\%) & $1(1.2 \%)$ \\
\hline Well (\%) & $0(0.0 \%)$ \\
\hline Managing well (\%) & $2(2.3 \%)$ \\
\hline Vulnerable (\%) & $9(10.5 \%)$ \\
\hline Mildly frail (\%) & $21(24.4 \%)$ \\
\hline Moderately frail (\%) & $9(10.5 \%)$ \\
\hline Severely frail (\%) & $26(30.2 \%)$ \\
\hline Very severely frail (\%) & $12(14.0 \%)$ \\
\hline Terminally ill (\%) & $6(7.0 \%)$ \\
\hline
\end{tabular}

psychoemotional support by affirming the caregiver's commitment to care for their loved one; reinforced the care and treatment plan; consolidated the patient's medications and hospital appointments; assessed and reinforced caregiver's competence in essential nursing skills such as wound care, injections, care of tubes and assessed the home environment for any fall risk or safety issues.
Several studies on transitional homecare have reported effectiveness at reducing caregiver burden, hospital readmissions, length of hospital stay, increased patient satisfaction, improved carer experience and increased emotional support. ${ }^{17-19}$

\section{Measures}

Demographic

A standard questionnaire was used to collect the patients' and caregivers' demographic details such as age, gender, race and marital status. Other patient variables included number of comorbidities, number of medications, cognitive, frailty and disability status. Other caregiver variables included educational status, employment status, living arrangement, duration of caregiving, relationship with the patient, additional help available from a foreign domestic helper and holding other responsibilities, such as taking care of young children or work commitments. Caregiver burden was measured using a self-administered caregiver burden questionnaire (online supplementary appendix 1). Cognitive status was measured using the Abbreviated Mental Test (AMT); this was a useful screening test for abnormal cognitive function in the elderly patient and the 10-question version was validated against clinical diagnoses of normal/abnormal cognitive function (by Diagnostic and Statistical Manual of Mental Disorders 3rd edition (DSM III R) criteria). ${ }^{20}$ Functional and frailty status was measured using the Clinical Frailty Scale (CFS) and disability was measured using the Modified Barthel Index (MBI). The CFS was easy to use; the assessor makes a clinical assessment and judgement about the degree of the patient's frailty that considers cognition, mobility, function and comorbidities, and assign a frailty level from 1 (very fit) to 9 (terminally ill, life expectancy $<6$ months). ${ }^{21}$ The MBI is a valid measure of disability; scores ranged from 0 to 20 , scores of $>16$ indicate independent, $<15$ indicate moderate disability and $<10$ indicate severe disability. ${ }^{22}$

Caregiver burden was measured using the ZBI 12-item questionnaire. Permission to use the ZBI was sought from the author and approved. The ZBI was widely referenced in studies of caregiver burden. ${ }^{23}$ The validity, reliability and sensitivity of the tool were widely studied and correlations between the full, short and screening versions were similar. $^{24}$ The short 12 -item version gave clinicians and researchers the opportunity to use an instrument that can be completed quickly without sacrificing validity. ${ }^{24}$ Each question was scored in a 5-point Likert scale; $0=$ never, $1=$ rarely, $2=$ sometimes, $3=$ quite frequently and $4=$ nearly always. Range of summed score was 0 to 48 and a score of 17 or more was identified as high burden. The brevity of this self-administered tool made it ideal for use in a busy tertiary hospital and in a variety of clinical setting such as home care and nurse-led clinics in the community. ${ }^{24}$

\section{Data analysis}

Descriptive statistics including numbers, percentage, mean and SD were used to detail the demographic 
Table 4 Baseline Zarit Burden Interview $(n=86)$

\begin{tabular}{|c|c|c|}
\hline Zarit Burden Interview & Mean estimation (SE) & $95 \% \mathrm{Cl}$ \\
\hline $\begin{array}{l}\text { Q1. Do you feel that because of the time you spend with your relative that } \\
\text { you do not have enough time for yourself? }\end{array}$ & $1.37(0.14)$ & 1.09 to 1.65 \\
\hline Q3. Do you feel angry when you are around your relative? & $0.57(0.09)$ & 0.38 to 0.76 \\
\hline Q5. Do you feel strained when you are around your relative? & $1.02(0.12)$ & 0.80 to 1.25 \\
\hline $\begin{array}{l}\text { Q6. Do you feel your health has suffered because of your involvement with } \\
\text { your relative? }\end{array}$ & $0.62(0.08)$ & 0.45 to 0.78 \\
\hline $\begin{array}{l}\text { Q7. Do you feel that you do not have as much privacy as you like because of } \\
\text { your relative? }\end{array}$ & $0.58(0.09)$ & 0.41 to 0.75 \\
\hline Q10. Do you feel uncertain about what to do about your relative? & $1.31(0.12)$ & 1.07 to 1.56 \\
\hline Q11. Do you feel you should be doing more for your relative? & $1.19(0.11)$ & 0.97 to 1.40 \\
\hline Q12. Do you feel you could do a better job in caring for your relative? & $1.16(0.11)$ & 0.94 to 1.38 \\
\hline
\end{tabular}

variables of the dyads. Non-parametric Wilcoxon signedrank test was used to examine the overall ZBI mean differences at baseline during hospital admission (T0) and at 30 days postdischarge (T1). Independent t-test was used to examine significant association between caregivers with high burden and caregivers with low burden. Statistical analysis was computed using STATA V.14.0 and statistical significance was set at the conventional $\mathrm{p}<0.05$, two-tailed.

\section{RESULTS}

\section{Description of participants}

During the study period, a total 86 patient-caregiver dyads (21\%) met the eligibility criteria and consented to participate in this study. The demographic details of the 86 dyads are described in tables 2 and 3, respectively. Majority of caregivers were aged above 40 years, female gender and of ethnic Chinese. Most were married, educated to secondary school level and holding a full-time job. Most caregivers lived with the patient $(71 \%)$ and had cared for their loved one for $>2$ years $(83 \%)$. Due to our culture of filial piety, most caregivers were either children $(62 \%)$ or spouses $(28 \%)$. Besides the caregiving role, $40 \%$ of caregivers reported holding other responsibilities such as work commitments or caring for young children. Almost half $(46.5 \%)$ had additional help from a foreign domestic helper, which is not uncommon in our local setting. The patients in this study were mostly aged 80 years and above $(57 \%)$, female gender and of ethnic Chinese. Most were moderately disabled (56\%) and severely frail $(30 \%)$. Half had more than five comorbidities (49\%) and were taking 5-10 different medications a day (49\%). A substantial number of patients has moderate-to-severe cognitive impairment $(40 \%)$.

\section{Baseline (TO) ZBI}

The mean difference, SE and 95\% CI of each of the items in the ZBI taken at baseline (T0) are described in table 4. The highest area of burden identified by most caregivers were: not enough time for self (mean=1.37, $\mathrm{SE}=0.14$, $95 \%$ CI 1.09 to 1.65 ); stress between caregiving and with other responsibilities (mean $=1.56, \mathrm{SE}=0.12,95 \%$ CI 1.32 to 1.80 ) and uncertain about what to do (mean=1.31, $\mathrm{SE}=0.12,95 \%$ CI 1.07 to 1.56$)$.

\section{Caregivers with high burden}

Of the 86 caregivers, 24 (28\%) caregivers scored $\geq 17$ on the ZBI at baseline (T0) assessment, indicating they had high caregiver burden. There was no statistical difference between the two groups of caregivers (those who scored $\mathrm{ZBI} \geq 17$ and $\mathrm{ZBI} \leq 17$ ) for variables: age, gender, race, marital status, education, employment status, living arrangement, duration of caregiving, relationship, additional help available and holding other responsibilities, except for frailty $(\mathrm{p}=0.036)$ (table 5$)$.

\section{Postintervention (T1) ZBI}

Eighty caregivers (93\%) completed the postintervention 30 days burden reassessment; six caregivers did not complete because the patient had deceased before any intervention was made. The difference in mean between the $\mathrm{ZBI}$ taken at baseline (T0) and at 30 days postdischarge (T1) for the 80 caregivers showed significant improvement in their burden level (T0 mean $=11.08, \mathrm{SD}=7.64$; T1 mean=2.48, $\mathrm{SD}=3.36$; Z-score difference $(\mathrm{T} 0-\mathrm{T} 1)=5.841$, $\mathrm{p} \leq 0.001)$. Seventy-three $(91 \%)$ caregivers showed positive improvement in caregiver burden (positive ranks, $\mathrm{p}<0.001$ ) with seven ties (no improvements). Caregivers with high burden $(\mathrm{n}=24)$ also reported significant 
Table 5 Description between caregivers with ZBI $\geq 17$ and ZBI $<17$

\begin{tabular}{|c|c|c|c|c|}
\hline Patient demographics & $\begin{array}{l}\text { Number of } \\
\text { patients }(n=80)\end{array}$ & $\begin{array}{l}\text { Number of caregivers } \\
\text { with } Z B I \geq 17(n=24)\end{array}$ & $\begin{array}{l}\text { Number of caregivers } \\
\text { with } Z B I<17(n=56)\end{array}$ & $P$ value \\
\hline Age (years) & & & & 0.616 \\
\hline $80(\%)$ & $45(56.3 \%)$ & $13(54.2 \%)$ & $32(57.1 \%)$ & \\
\hline $61-80(\%)$ & $29(36.3 \%)$ & $8(33.3 \%)$ & $21(37.5 \%)$ & \\
\hline $41-60(\%)$ & $5(6.3 \%)$ & $3(12.5 \%)$ & $2(3.6 \%)$ & \\
\hline$<40(\%)$ & $1(1.3 \%)$ & $0(0.0 \%)$ & $1(1.8 \%)$ & \\
\hline Gender & & & & 0.207 \\
\hline Female (\%) & $52(65.0 \%)$ & $18(75.0 \%)$ & $34(60.7 \%)$ & \\
\hline Male (\%) & $28(35.0 \%)$ & $6(25.0 \%)$ & $22(39.7 \%)$ & \\
\hline Race & & & & 0.582 \\
\hline Chinese (\%) & $70(87.5 \%)$ & $22(91.7 \%)$ & $48(85.7 \%)$ & \\
\hline Malay (\%) & $8(10.0 \%)$ & $2(8.3 \%)$ & $6(10.7 \%)$ & \\
\hline Indian (\%) & $2(2.5 \%)$ & $0(0.0 \%)$ & $2(3.6 \%)$ & \\
\hline Modified Barthel Index & & & & 0.340 \\
\hline$<15$ (moderate disability) (\%) & $44(55.0 \%)$ & $15(62.5 \%)$ & $29(51.8 \%)$ & \\
\hline$>16$ (independent) (\%) & $26(32.5 \%)$ & $6(25.0 \%)$ & $20(35.7 \%)$ & \\
\hline$<10$ (severe disability) (\%) & $10(12.5 \%)$ & $3(12.5 \%)$ & 7 (12.5\%) & \\
\hline Number of comorbidities & & & & 0.799 \\
\hline$>5(\%)$ & $39(48.8 \%)$ & $12(50.0 \%)$ & $27(48.2 \%)$ & \\
\hline $2-5(\%)$ & $33(41.3 \%)$ & $10(41.7 \%)$ & $23(41.1 \%)$ & \\
\hline$<2(\%)$ & $8(10.0 \%)$ & $2(8.3 \%)$ & $6(10.7 \%)$ & \\
\hline Abbreviated Mental Test & & & & 0.289 \\
\hline$>6$ (mild/no impairment) (\%) & $48(60.0 \%)$ & $13(54.2 \%)$ & $35(62.5 \%)$ & \\
\hline 0-3 (severe impairment) (\%) & $19(23.8 \%)$ & $8(33.3 \%)$ & $11(19.6 \%)$ & \\
\hline 4-6 (moderate impairment) (\%) & $13(16.3 \%)$ & $3(12.5 \%)$ & $10(17.9 \%)$ & \\
\hline Number of medications & & & & 0.731 \\
\hline $5-10(\%)$ & $39(48.8 \%)$ & $10(41.7 \%)$ & $30(53.6 \%)$ & \\
\hline$>10(\%)$ & $29(36.3 \%)$ & $9(37.5 \%)$ & 19 (33.9\%) & \\
\hline$<5(\%)$ & $12(15.0 \%)$ & $5(20.8 \%)$ & $7(12.5 \%)$ & \\
\hline Clinical frailty score & & & & 0.036 \\
\hline Very fit (\%) & $1(1.3 \%)$ & $0(0.0 \%)$ & $1(1.8 \%)$ & \\
\hline Well (\%) & $0(0.0 \%)$ & $0(0.0 \%)$ & $0(0.0 \%)$ & \\
\hline Managing well (\%) & $2(2.5 \%)$ & $0(0.0 \%)$ & $2(3.6 \%)$ & \\
\hline Vulnerable (\%) & $9(11.3 \%)$ & $0(0.0 \%)$ & $9(16.1 \%)$ & \\
\hline Mildly frail (\%) & $20(25.0 \%)$ & $6(25.0 \%)$ & $14(25.0 \%)$ & \\
\hline Moderately frail (\%) & $8(10.0 \%)$ & $2(8.3 \%)$ & $6(10.7 \%)$ & \\
\hline Severely frail (\%) & $23(28.8 \%)$ & $11(45.8 \%)$ & $12(21.4 \%)$ & \\
\hline Very severely frail (\%) & $12(15.0 \%)$ & $4(16.7 \%)$ & $8(14.3 \%)$ & \\
\hline Terminally ill (\%) & $5(6.3 \%)$ & $1(4.2 \%)$ & $4(7.1 \%)$ & \\
\hline
\end{tabular}

improvement in their mean burden scores postintervention $(\mathrm{T} 0$ mean=20.5, $\mathrm{SD}=4.746$; $\mathrm{T} 1$ mean $=6.33, \mathrm{SD}=3.266$; positive ranks, $\mathrm{p}<0.000)$.

\section{DISCUSSION}

This study provided valuable insights that identifying caregiver burden as early as on admission using a structured assessment tool and initiating robust targeted interventions were effective at reducing caregiver burden. The help rendered to the caregivers sustained them in their ability to continue to provide care at home. Caregiver 
burden was presented in several different aspects in this study; physical, financial, emotional and psychosocial strain. Most of the patients had high care needs-the elderly, multiple comorbidities, polypharmacy, frailty, disability and cognitive impairment. Almost half of the caregivers were holding a full-time job and juggling their time between caregiving and holding other responsibilities, although having additional help from a foreign domestic helper.

Similar findings were also reported in literatures where high caregiver burden was more prevalent among caregivers of patients with increased frailty or disability, ${ }^{25}$ and caregivers of patients with advanced comorbidities (such as dementia, cancer, chronic obstructive pulmonary disease, heart failure) and the need for more help with daily tasks. ${ }^{26}{ }^{27}$ The caregiving burden of caregivers of people with dementia was largely related to the constant caring, deterioration of functional capacity and the need to invest a great deal of time and effort in the caregiving task. ${ }^{27-29}$ Caregivers who provided longer hours of caregiving also experienced higher level of burden. ${ }^{27}$

The highest areas of burden identified by most caregivers in this study were: personal strain (ie, juggling between caregiving and time for own self); trying to meet other responsibilities and uncertain about what to do in caring for their loved one. By recognising the different aspects of caregiver burden early, PNs were able to intervene and focus their interventions timely and more efficiently. For example, in areas of high personal strain (ie, juggling between caregiving and time for own self) and trying to meet other responsibilities, PN had assisted with the application of day care services or respite care to support and provide some relief for the caregiver. In the area of uncertain about what to do in caring for their loved one, PN facilitated the individualised caregiver training, patient family education on chronic disease and medication, application of equipment such as hospital bed and continued support postdischarge. The implementations has improved the PNs' work efficiency and process, and there was better staff and patient-caregiver satisfaction as care is more timely and individualised.

The ZBI tool was useful at quantifying caregiver burden at the initial diagnostic assessment $t^{30}$ and feasible to use in a busy tertiary hospital. The self-administered questionnaire was user friendly and allowed for an honest reflection and answer. To ensure there was consistency in the assessment and practice among PNs; audits, trainings and clinical guidance were provided during the daily huddle and discussions. Incorporating the ZBI into the PNs workflow and patient care assessment was essential to the sustainability and scalability of this project. The regular communication meetings with team members and feedback facilitated the buy-in of the project's initiatives. Additional elements critical to the success of this study was the engagement of key stakeholders and the project team's dedication in the implementation and dissemination process.

\section{Study limitations}

Our study has several limitations; the study design did not include a control group (usual care) and the sampling methodology only included dyads who met the eligibility criteria. Dyads that refused home visits or telephone calls were excluded, making it difficult to ascertain if the caregivers had high levels of burden. Future studies to include other variables such as family dynamics, coping styles, underlying comorbidities of the caregiver and measuring patient outcomes such as hospital readmission, length of stay, quality of life or satisfaction level. Additional analysis such as correlations between caregiver burden and the patient's length of hospital stay, the number of times the PN met with the caregiver/patient and the number of interventions received are also useful as these factors may have influenced the results.

\section{CONCLUSION}

The period after hospitalisation is stressful as there is often lack of care continuity post-discharge and chronic disease progression in combination with inadequate care. ${ }^{31} 32$ This study identified the importance of using a well-structured caregiver burden assessment tool, such as the ZBI in the early recognition and intervention of caregiver burden. Robust and targeted PN interventions during hospitalisation, such as an individualised caregiver training and transitional homecare facilitated the safe and smooth care transition from hospital to home. Caregiver support extended beyond hospital discharge was vital, as patients may develop new problems only after discharge ${ }^{33}$ Having a dedicated PN in the hospital to facilitate the care assessment, education and discharge planning process, provided the additional support to patients and their caregivers during the hospital to home transition.

Contributors Each member played an important and active role. LLL, CH and TSB are content experts and they assisted with the discussions, planning, dissemination, evaluation of data and editing of the project's manuscript. RMT is the project lead and the nursing supervisor for the PNs. RMT led the planning, implementation, assisted the PNs with data collation, analysis and writing of the project's manuscript.

Funding The authors have not declared a specific grant for this research from any funding agency in the public, commercial or not-for-profit sectors.

\section{Competing interests None declared.}

Patient and public involvement Patients and/or the public were not involved in the design, conduct, reporting or dissemination plans of this research.

Patient consent for publication Not required.

Provenance and peer review Not commissioned; externally peer reviewed.

Data availability statement Data are available upon request.

Open access This is an open access article distributed in accordance with the Creative Commons Attribution Non Commercial (CC BY-NC 4.0) license, which permits others to distribute, remix, adapt, build upon this work non-commercially, and license their derivative works on different terms, provided the original work is properly cited, appropriate credit is given, any changes made indicated, and the use is non-commercial. See: http://creativecommons.org/licenses/by-nc/4.0/.

ORCID iD

Rachel Marie Towle http://orcid.org/0000-0002-5266-7574 


\section{REFERENCES}

1 Ministry of health. ageing in Singapore in the next 50 years. Speech by Mr Gan Kim Yong, Minister for Health at the SG50 Scientific Conference on Ageing 2015 https://www.moh.gov.sg/content/moh_ web/home/costs_and_financing/schemes_subsidies/medisave/ Chronic Diseases.html (accessed 10 December 2017).

2 Reinhard SC, Choula R. Meeting the needs of diverse family caregivers: AARP public policy Institute, 2012. Available: https:// www.aarp.org/content/dam/aarp/research/public_policy_institute/ltc/ 2012/meeting-needs-diverse-family-caregivers-insight-AARP-ppi-Itc. pdf [Accessed 1 January 2018].

3 Bucher JA, Loscalzo M, Zabora J, et al. Problem-Solving cancer care education for patients and caregivers. Cancer Pract 2001;9:66-70.

4 Alliance FC, Principles Caregiver Assessment:. Guidelines and strategies for change, 2006. Available: https://www.caregiver.org/ sites/caregiver.org/files/pdfs/v1_consensus.pdf [Accessed 27 December 2017].

5 Feinberg L. Assessing family and caregivers needs: policy and practice considerations. AARP public policy Institute, 2012. Available: http://www.caregiving.org/wp-content/uploads/2010/11/ AARP-caregiver-fact-sheet.pdf [Accessed 3 March 2018].

6 Grant JS, Graven LJ. Problems experienced by informal caregivers of individuals with heart failure: an integrative review. Int J Nurs Stud 2018;80:41-66.

7 Deeken JF, Taylor KL, Mangan P, et al. Care for the caregivers: a review of self-report instruments developed to measure the burden, needs, and quality of life of informal caregivers. J Pain Symptom Manage 2003;26:922-53.

8 Blair J, Volpe M, Aggarwal B, Challenges AB. Challenges, needs, and experiences of recently hospitalized cardiac patients and their informal caregivers. J Cardiovasc Nurs 2014;29:29-37.

9 Goode KT, Haley WE, Roth DL, et al. Predicting longitudinal changes in caregiver physical and mental health: a stress process model. Health Psychology 1998;17:190-8.

10 Yaffe K, Fox P, Newcomer R, et al. Patient and caregiver characteristics and nursing home placement in patients with dementia. JAMA 2002;287:2090-7.

11 Bull MJ, Hansen HE, Gross CR. Differences in family caregiver outcomes by their level of involvement in discharge planning. Appl Nurs Res 2000;13:76-82.

12 Reinhard SC, Given B, Petlick NH, et al. Supporting family caregivers in providing care. AARP public policy Institute, 2008. Available: https://www.ncbi.nlm.nih.gov/books/NBK2665/ [Accessed 15 February 2018].

13 Naylor MD. Transitional care of older adults. Annu Rev Nurs Res 2002;20:127-47

14 Gaugler JE, Roth DL, Haley WE, et al. Can Counseling and support reduce Alzheimer's caregivers' burden and depressive symptoms during the transition to institutionalization? Journal Am Geriatric Society 2008;56:421-8.

15 Mustapha NZB, Yi X, Razali M, et al. The role of patient navigators: case studies in Singapore. Proceedings of Singapore Healthcare, 2016.
16 Kwok T, Wong B, Ip I, et al. Telephone-delivered psychoeducational intervention for Hong Kong Chinese dementia caregivers: a singleblinded randomized controlled trial. Clin Interv Aging 2013;8:1191.

17 Allen J, Hutchinson AM, Brown R, et al. Quality care outcomes following transitional care interventions for older people from hospital to home: a systematic review. BMC Health Serv Res 2014;14:346.

18 Shyu YI. The needs of family caregivers of frail elders during the transition from hospital to home: a Taiwanese sample. J Adv Nurs 2000;32:619-25.

19 Jencks SF, Williams MV, Coleman EA. Rehospitalizations among patients in the Medicare fee-for-service program. $N$ Engl J Med 2009;360:1418-28.

20 Chu LW, CKW P, MH H, et al. Validation of the abbreviated mental test (Hong Kong version) in the elderly medical patient. Hong Kong Medical Journal 1995;1:207-11.

21 Wallis SJ, Wall J, Biram RWS, et al. Association of the clinical frailty scale with hospital outcomes. QJM 2015;108:943-9.

22 Collin C, Wade DT, Davies S, et al. The Barthel ADL index: a reliability study. Int Disabil Stud 1988;10:61-3.

23 Parks SM, Novielli KD, Burden C, Quite NRS. A practical guide to caring for caregivers. Am Fam Physician 2000;62:2613-20.

24 Bedard M, Molloy DW, Squire L, et al. The Zarit burden interview: a new short version and screening version. The Gerontologist 2011;41:652-7.

25 Rinaldi P, Spazzafumo L, Mastriforti R, et al. Study group of brain aging of the Italian Society of gerontology and geriatrics. predictors of high level of burden and distress in caregivers of demented patients: results of an Italian multicenter study. International Journal of Geriatric Psychiatry 2005;20:168-74.

26 Garlo K, O'Leary JR, Van Ness PH, Fried TR, et al. Burden in caregivers of older adults with advanced illness. J Am Geriatr Soc 2010;58:2315-22.

27 Kim H, Chang M, Rose K, Heejung K, Mido C, Karen R, et al. Predictors of caregiver burden in caregivers of individuals with dementia. J Adv Nurs 2012;68:846-55.

28 Motenko AK. The frustrations, gratifications, and well-being of dementia caregivers. Gerontologist 1989;29:166-72.

29 Sharpe L, Butow P, Smith C, et al. The relationship between available support, unmet needs and caregiver burden in patients with advanced cancer and their carers. Psychooncology 2005;14:102-14.

30 Stagg B, Larner AJ. Zarit burden interview: pragmatic study in a dedicated cognitive function clinic. Neurology and Psychiatric 2015 https://onlinelibrary.wiley.com/doi/abs/ (accessed 11 December 2017).

31 Coleman EA. Falling through the cracks: challenges and opportunities for improving transitional care for persons with continuous complex care needs. J Am Geriatr Soc 2003;51:549-55.

32 Harrison PL, Hara PA, Pope JE, et al. The impact of postdischarge telephonic follow-up on hospital readmissions. Popul Health Manag 2011;14:27-32.

33 Altfeld SJ, Shier GE, Rooney M, et al. Effects of an enhanced discharge planning intervention for hospitalized older adults: a randomized trial. Gerontologist 2013;53:430-40. 